\title{
Data Acquisition Method for Measuring Mycelium Growth of Microorganism with GIS*
}

\author{
Juan Yang ${ }^{1, * *}$, Jingyin Zhao ${ }^{1}$, Qian Guo ${ }^{2}$, Yunsheng Wang ${ }^{1}$, and Ruijuan Wang ${ }^{2}$ \\ ${ }^{1}$ Technology \& Engineering Research Center for Digital Agriculture, \\ Shanghai Academy of Agricultural Sciences, Shanghai 201106, P.R. China \\ ${ }^{2}$ Institute of Edible Fungi, Shanghai Academy of Agricultural Sciences, Shanghai 201106, \\ P.R. China \\ yangjuan@saas.sh.cn
}

\begin{abstract}
Mycelium is the vegetative part of a fungus or most microorganisms, consisting of a mass of branching, thread-like hyphae. It is through the hyphae that a fungus absorbs nutrients from its environment. For most fungi, the ability of nutrition translation from mycelium to fruit body is determined by growth status of hyphae. It is very necessary to study the effect of environmental factors on mycelium growth, and know the befitting environment condition. However, finding a good data acquisition method for measuring the mycelium is the key point.

A new method was introduced in the paper. The method is using image identification and space data analysis function of the GIS to acquire development rate of mycelium i.e. hyphae. Pleurotus eryngii under commercial production is taken as example. The effect of different temperature and humidity on mycelium growth was analyzed. It is hoped to explore a new method for scientific and precise measurement the growth status and development rate of mycelium.
\end{abstract}

Keywords: mycelium, data acquisition, microorganism, Pleurotus eryngii.

\section{Introduction}

Mycelium is the vegetative part of a fungus or most microorganisms, consisting of a mass of branching, thread-like hyphae. It is through the hyphae that a fungus absorbs nutrients from its environment. Hyphae are very wispy and only several microns long. The structure of hyphae only can be observed by microscope, so the growth of hyphae is usually expressed by morphologic change of mycelium. There are two methods to measure mycelium growth at present. The first method is physical method. By checking the space change of the mark on the forepart of a mycelium or the diameter change of a mycelium in certain period of time, the growth of the mycelia can be observed. However, this method has a big error, moreover, it only adapts to the smooth

\footnotetext{
* The research was supported by the project of the Science and Technology Commission of Shanghai Municipality, China (grant No. 08DZ2210600 and No. 08QA14058) and the National Natural Science Foundation of China (grant No. 30800765).

** Corresponding author.
} 
agar substrate in laboratory [1] and can not be used in nature or in production of edible fungi. For the circumstances outside the laboratory, the substrate is often rough surfaced soil or the admixture of wood chip, corncob chip and so on. Another approach is to measure the fungal-specific biochemical markers [2], which is classified

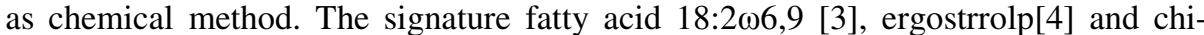
tin[5] have been used as a marker for ectomycorrhizal(EM) fungi[7-8], and the neutral lipid fatty acid 16:1 155 has been used as a marker for arbuscular mycorrhizal(AM) fungi[8]. For example, ergosterol is a fungus specific lipid used as a marker for living fungal biomass $[4,6]$, by quantifying its ergosterol content where the activity of mycelium was determined[9]. There is another situation for some fungi that the target production is the antiviral, antibacterial or antifungal substances from its secondary metabolites, such as Pycnoporus sanguineus, which produces an important secondary metabolite, cinnabarin. The growth of the fungus was represented by the cinnabarin production [10].

However, most fungi or microorganisms do not have the specific biochemical matters in them. How to quantitatively express the growth of mycelium i.e. hyphae? A new method named photogrammetry was introduced in the paper for measuring the growth of mycelium. The approach was also applied in the GIS data acquisition [11]. The key of the approach is using image identification and space data analysis function of the GIS software. Then the mycelium of Pleurotus eryngii under commercial production was taken as example. The effect of different temperature and humidity on mycelium growth was analyzed. The aim of this paper is to explore a new method for scientific and precise measurement of growth status and development rate of mycelium.

\section{Materials and Methods}

\section{Mycelium Living in All Kinds of Substrate}

The method is not only appropriate for measuring the growth of mycelium living in the smooth agar substrate in laboratory experiments, but also for the mycelium living in almost all kinds of substrate, for example, the mycelium of Agaricus bisporus(Lange) Sing. living in the soil, the mycelium of Pleurotus eryngii living in the admixture of wood chip, corncob chip and so on.

It needs to mention that the method is not applicable for EM fungi or AM fungi, in which the mycelium accretes with plant roots and forms a symbiont. There are no methods having been available to distinguish mycelia from EM fungi or AM fungi from saprotrophic fungal mycelia in soil [7]. Therefore, the amount of EM fungi or AM fungi is usually calculated by the chemical method, which is reflected by their specific compounds.

\section{Image Acquisition}

The strongpoint of this method is that it is no need to destroy the growth of mycelium or touch the mycelium in data acquisiton, so the process and trends of growth of hyphae can be monitored. 
The image of mycelium can be obtained by digital cameras with at least $1024 \times 768$ pixels or 300 resolutions.

\section{Image Processing}

The obtained photo is usually a color image, which has three bands, respectively, red (band_1), green (band_2) and blue (band_3). Through opening the band image of the color image in the ArcMap software, the monochrome image of the color image can be obtained. In the monochrome image, each pixel has a gray value (usually between 0 and 255) that specifies a particular shade of gray. Black is 0 and white is 255 .

Taking the mycelium of Pleurotus eryngii as example, the hyphae live in the substrate loaded in the bottle, and the mycelium revealed on the bottle mouth is a window that reflects the growth of the hyphae. The picture of the mycelium on the bottle mouth was taken and opened in the ArcMap software. In the band_3 (blue) image of the three band image, the contrast between mycelium and substrate is the biggest one(see Fig.1). The second step is extracting the region to be analyzed on the photo by the Spatial Analyst Tools__Extraction of the ArcGIS. That is, the useless region is removed (see Fig.2B) and the Object Image Layer is obtainded.
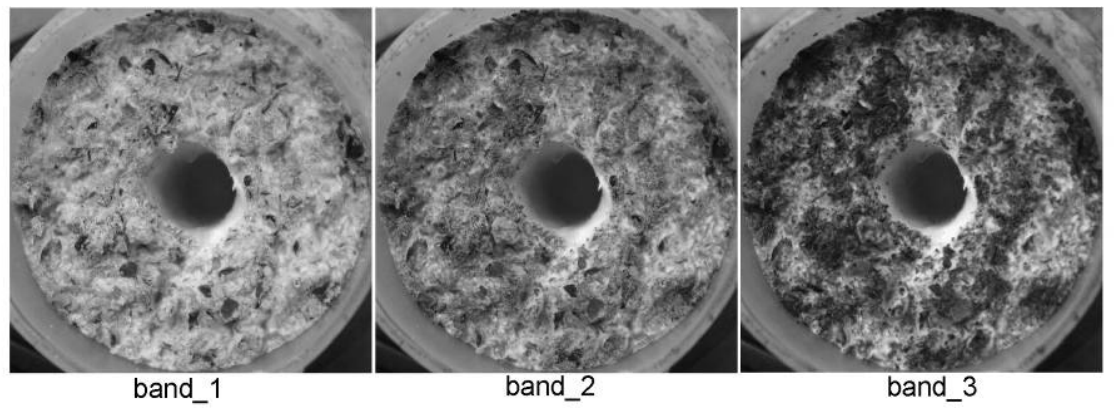

Fig. 1. Three band image of the acquired color image

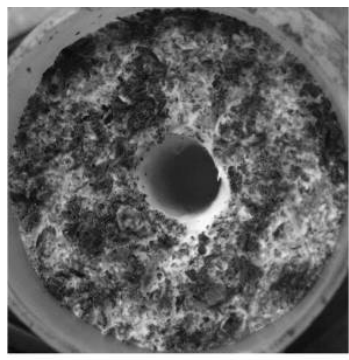

A

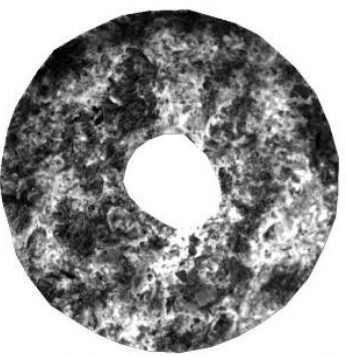

$\mathrm{B}$

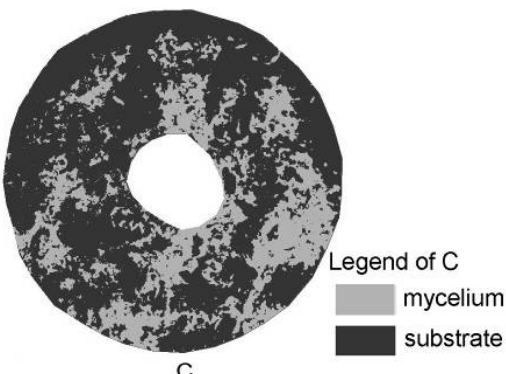

$\mathrm{C}$

Fig. 2. The key image layer in the method

A.the original image; B. the image that useless region was removed; C. the raster layer of substrate and mycelium pixel. 


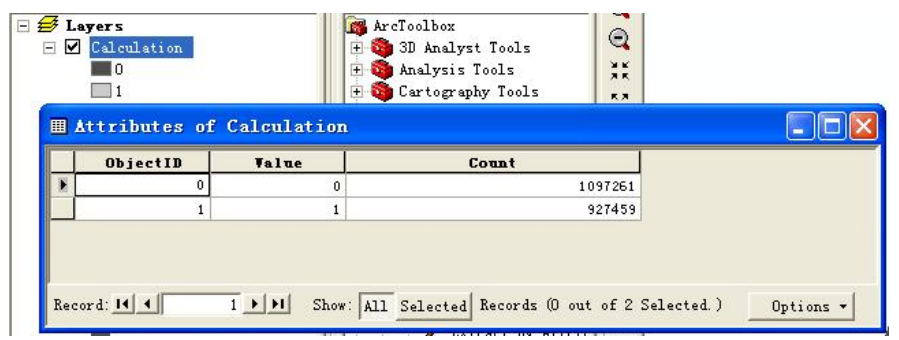

Fig. 3. The raster count of the two pixel value in the Attribute Table of the ArcGIS

\section{Data Acquisition}

With the identification tool in the ArcGIS, the gray value of each pixel can be identified. Because the color of Pleurotus eryngii mycelium is white and the color of substrate is much darker, the gray value tends to 0 for the pixel of Pleurotus eryngii mycelium and to 255 for the pixel of the substrate. It is important to confirm the critical gray value between the mycelium pixel and the substrate pixel. With the critical gray value, a new raster layer can be got by using the Raster Calculator tool of the Spatial Analyst Tools in the ArcGIS (see Fig.2C).

In the new raster layer, the pixel of mycelium is valued 1 and the pixel of substrate is valued 0 if input formula in the Raster Calculator tool shows " 'the Object Image Layer' > 'the critical gray value' ", or the pixel of mycelium is valued 0 and the pixel of substrate is valued 1 if input formula in the Raster Calculator tool shows " "the Object Image Layer' < 'the critical gray value' ". Opening the Attribute Table of the raster layer, the raster count of two pixel values is displaying (see Fig.3). The proportion of mycelium can be calculated through the raster count of mycelium divided by the sum of the raster count of mycelium and substrate. By monitoring the development of the proportion of mycelium in unit times, the development rate of hyphae can be expressed.

\section{Application and Discussion}

\section{Background}

An example about the effect analysis of temperature and humidity for mycelium growth is given to illustrate the application of the method.

There are two phases for the hyphae of Pleurotus eryngii under commercial production. In the first phase, the strains of Pleurotus eryngii are inoculated into the culture medium loaded in plastic bottle. Then the bottle with the strains is incubated under conditions at $25^{\circ} \mathrm{C}, 70-75 \% \mathrm{RH}$ about 25 days, and it is still kept in this situation about 10 days for afterripening after the hyphae spreading into the entire bottle. On top of the bottle, lid is removed and the surface of the culture medium is mechanically scratched to remove the exterior aerial mycelium and a $15 \mathrm{~mm}$ layer of substrate. This process is used to induce uniform formation of primordia with synchronous mushroom production [12]. The opened bottles are placed in a production room 
controlled at temperature about $18^{\circ} \mathrm{C}, 85-95 \% \mathrm{RH}$. The hyphae are entering into the second development phase.

The second phase is very important, especially the hyphae in the surface of the culture medium are important because they will kink into the bud of mushroom. The air climate control systems for the growing rooms are designed and manufactured by Patron AEM in Netherlands in this study. These unique systems are able to control temperature, humidity and $\mathrm{CO}_{2}$ concentration in growing rooms very precisely and efficiently.

In the experiment of the example in this study, treatments included temperature at $14^{\circ} \mathrm{C}, 15^{\circ} \mathrm{C}, 16^{\circ} \mathrm{C}, 17^{\circ} \mathrm{C}$ and $18^{\circ} \mathrm{C}$ with $97 \% \mathrm{RH}$, and relative humidity at $89 \%, 91 \%$, $93 \%, 95 \%$ and $97 \%$ at $16^{\circ} \mathrm{C}$. Three replicates for each treatment were set. The experiment was a 2 (supplement) $\times 5$ (treatment) design with 3 replicates per treatment. The mycelium growth was measured daily (every 24 hours) at 8 bottles for each experiment. Each value is the mean of 24 measured results ( 3 replicates $\times 8$ bottles).

\section{Results and Analysis}

In the mycelium growth stage, the mycelium proportion showed remarkable change in different days (Tab.1). The mycelium growth followed the theoretical logistic growth curve exactly (Fig.4).

Table 1. Pleurotus eryngii mycelium growth at different times

\begin{tabular}{ccccccc}
\hline time $/ \mathrm{d}$ & 1 & 2 & 3 & 4 & 5 & 6 \\
\hline $\begin{array}{c}\text { mycelium } \\
\text { proportion (\%) }\end{array}$ & $18.13 \%^{\mathrm{a}}$ & $27.70 \%^{\mathrm{b}}$ & $44.47 \%^{\mathrm{c}}$ & $56.49 \%^{\mathrm{d}}$ & $63.79 \%^{\mathrm{e}}$ & $67.29 \%^{\mathrm{f}}$ \\
\hline
\end{tabular}

${ }^{1}$ The mycelium proportion was each day's means of two treatments. Different letters indicate statistically different values $($ ANOVA/LSD) $(\mathrm{P}<0.05)$.

The effects of temperature on mycelium of Pleurotus eryngii over a range of temperatures from $14^{\circ} \mathrm{C}$ to $18^{\circ} \mathrm{C}$ are shown in Fig. $4 \mathrm{~A}$ and the effects of humidity over a range of relative humidity from $89 \%$ to $97 \%$ are shown in Fig.4B. The mycelium proportion showed a biggish difference at temperature from $14^{\circ} \mathrm{C}$ to $18^{\circ} \mathrm{C}$. As the temperature increases, the mycelium development rate grows faster. It is indicated that the temperature of $17^{\circ} \mathrm{C}$ and $18^{\circ} \mathrm{C}$ for mycelium growth is much better than other temperatures. The mycelium development rate also grows faster as the RH increases. However, there is no difference in the mycelium proportion under RH from $89 \%$ to $97 \%$.

The above results can also be shown from the statistically multiple comparisons (Tab. 2). At different temperature, the mycelium developed the fastest at $17^{\circ} \mathrm{C}$, followed by $18^{\circ} \mathrm{C}, 16^{\circ} \mathrm{C}, 15^{\circ} \mathrm{C}$ and $14^{\circ} \mathrm{C}$. And there is remarkable difference for the mycelium proportion among $17^{\circ} \mathrm{C}$ and $18^{\circ} \mathrm{C}, 16^{\circ} \mathrm{C}$, as well as among $18^{\circ} \mathrm{C}, 16^{\circ} \mathrm{C}$ and $15^{\circ} \mathrm{C}, 14^{\circ} \mathrm{C}$. Under different humidity, the mycelium developed the fastest under $95 \%$ and $93 \% \mathrm{RH}$, followed by $97 \%, 89 \%$ and $91 \% \mathrm{RH}$. However, in the experience, it was found that the surface of the substrate was very dry under $93 \%$ RH during the late stage of mycelium growth, and the kinked buds of mushroom were less. 


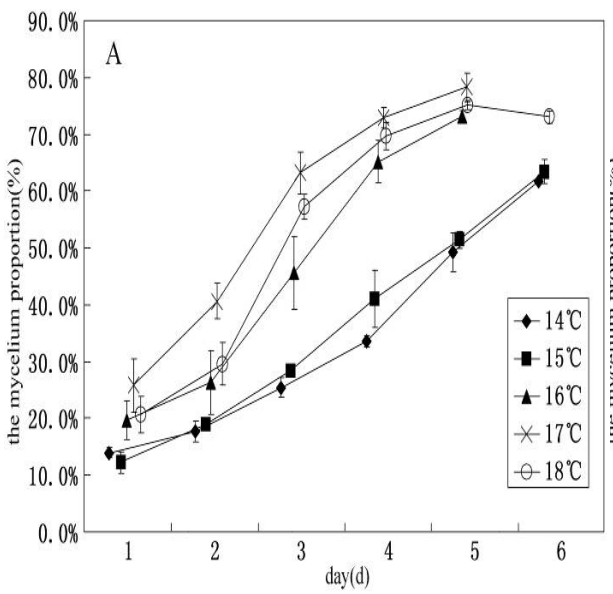

(a)

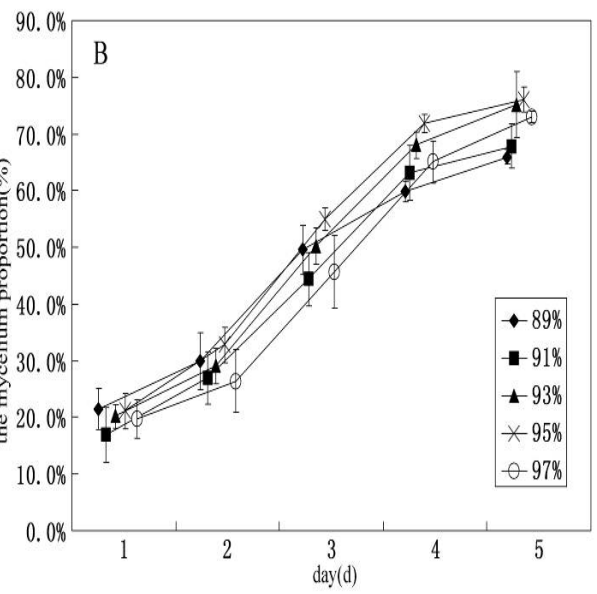

(b)

Fig. 4. Growth of Pleurotus eryngii mycelium incubated at different temperatures and relative humidity. (a) temperature treatment. (b) Humidity treatment.

Table 2. Effect of temperature and humidity on growth of Pleurotus eryngii mycelium

\begin{tabular}{cc|cc}
\hline $\begin{array}{r}\text { Treatment } \\
\text { temperature) }\end{array}$ & $\begin{array}{c}\text { mycelium } \\
\text { proportion (\%) }\end{array}$ & $\begin{array}{c}\text { Treatment } \\
\text { (humidity) }\end{array}$ & $\begin{array}{c}\text { mycelium } \\
\text { proportion (\%) }\end{array}$ \\
\hline $17^{\circ} \mathrm{C}$ & $0.5979^{\mathrm{a}}$ & $95 \%$ & $0.5546^{\mathrm{a}}$ \\
$18^{\circ} \mathrm{C}$ & $0.5371^{\mathrm{b}}$ & $93 \%$ & $0.5279^{\mathrm{ab}}$ \\
$16^{\circ} \mathrm{C}$ & $0.5054^{\mathrm{b}}$ & $97 \%$ & $0.5054^{\mathrm{bc}}$ \\
$15^{\circ} \mathrm{C}$ & $0.3600^{\mathrm{c}}$ & $89 \%$ & $0.4883^{\mathrm{c}}$ \\
$14^{\circ} \mathrm{C}$ & $0.3350^{\mathrm{c}}$ & $91 \%$ & $0.4821^{\mathrm{c}}$ \\
\hline
\end{tabular}

${ }^{1}$ The mycelium proportion was the means of different treatments. Different letters indicate statistically different values $($ ANOVA/LSD) $(\mathrm{P}<0.05)$.

Through comprehensive analysis of the data, it is believed that the optimal temperature and humidity conditions for mycelium growth in the growing room is $16^{\circ} \mathrm{C}$ and above, and $95 \% \mathrm{RH}$ and above.

Using this method, the growth of mycelium can be dynamically monitored with no mycelium being destroyed. In addition to this, with the same principle of the method in this paper, in combination with computer image analysis, microscopy can be used in the study of microorganism structure. And the latter method has been used to quantify the growth, number and shape of cells in the different tissues of ageing mushrooms [13].

\section{Conclusion}

GIS can be used for a wide range of applications such as urban and regional planning, agriculture, and wildlife and natural resource management. GIS is capable of capturing, storing, manipulating, and displaying spatial reference information to allow for 
efficient data organization and access. The method introduced in the paper can be named photogrammetry. It mainly uses image identification and space data analysis function of the GIS.

Three steps are included in the method, that is, image acquisition, image processing and data acquisition. Thereinto, the last two steps are the key. Image analysis is also one of the major research tasks in photogrammetry currently [11].

The method is not only appropriate for measuring the growth of mycelium living in the smooth agar substrate in laboratory experiments, but also for the mycelium living in almost all kinds of substrate. From the examples taken in the paper, it can be seen that the growth of mycelium can be dynamically and quantatively monitored with no mycelium being destroyed by using the method.

\section{References}

[1] Bending, G.D., Read, D.J.: The structure and function of the vegetative mycelium of ectomycorrhizal plants VI. Activities of nutrient mobilizing enzymes in birch litter colonized by Paxillus involutus (Fr.) Fr. New Phytologist 130, 411-417 (1995)

[2] Olsson, P.A.: Signature fatty acids provide tools for determining of the distribution and interactions of mycorrhizal fungi in soil. FFMS Microbiology Ecology 29, 303-310 (1999)

[3] Olsson, P.A., Johansen, A.: Lipid and fatty acid composition of hyphae and spores of arbuscular mycorrhizal fungi at different growth stages. Mycological Research 104, 429 434 (1996)

[4] Nylund, J.E., Wallander, H.: Ergosterol analysis as a means of quantifying mycorrhizal biomass. In: Norris, J.R., Read, D.J., Varma, A.K. (eds.) Methods in Microbiology, vol. 24, pp. 77-88. Academic Press, London (1992)

[5] Ekblad, A., Näsholm, T.: Determination of chitin in fungi and mycorrhizal roots by an improved HPLC analysis of glucosamine. Plant and Soil 178, 29-35 (1996)

[6] Ekblad, A., Wallander, H., Näsholm, T.: Chitin and ergosterol combined to measure total and living biomass in ectomycorrhizae. New Phytologist 138, 143-149 (1998)

[7] Wallander, H., Nilsson, L.O., Hagerberg, D., Baath, E.: Estimation of the biomass and seasonal growth of external mycelium of ectomycorrhizal fungi in the field. New Phytologist 151, 753-760 (2001)

[8] Olsson, P.A., Johansen, A.: Lipid and fatty acid composition of hyphae and spores of arbuscular mycorrhizal fungi at different growth stages. Mycological Research 104(4), 429-434 (2000)

[9] Carrillo, C., Díaz, G., Honrubia, M.: Improving the Production of Ectomycorrhizal Fungus Mycelium in a Bioreactor by Measuring the Ergosterol Content. Engineering in Life Sciences 4(1), 43-45 (2004)

[10] Duarte, B.J., Maria, M.D.S., Pacheco Sabrina, M.V., et al.: Comparative study of mycelial growth and production of cinnabarin by different strains of Pycnoporus sanguineu. BioFar. 2(2), 1-5 (2008)

[11] Heipke, H., Pakzad, K., Straub, B.M.: Image Analysis for GIS Data Acquisition. The Photogrammetric Record 16, 963-985 (2003)

[12] Rodriguez Estrada, A.E., Royse, D.J.: Yield, size and bacterial blotch resistance of Pleurotus eryngii grown on cottonseed hulls/oak sawdust supplemented with manganese, copper and whole ground soybean. Bioresource Technology 98, 1898-1906 (2007)

[13] Braaksma, A., van Doorn, A.A., Kieft, H., van Aelst, A.C.: Morphometric analysis of ageing mushrooms (Agaricus bisporus) during postharvest development. Postharvest Biology and Technology 13, 71-79 (1998) 